\title{
Entrevista com Karl Erik Schollhammer ${ }^{1}$
}

ENTREVISTA por Maria Cristina Ribas e Carlinda Nuñez PARA DOSSIÊ No 32 (2016.2) Soletras, Uerj

Soletras - Qual o seu entendimento sobre a ênfase na busca pelo "efeito de realidade" que atravessa as produções lítero-culturais da contemporaneidade?

Meu trabalho tem mostrado uma procura não apenas por um "efeito do real", no sentido de Roland Barthes, mas pelo real mesmo! Tanto na literatura como no teatro, na fotografia, no cinema e na mídia em particular, observamos uma demanda de realidade que extrapola as fronteiras do realismo histórico. Neste sentido, tenho acompanhado o desenvolvimento das formas representativas muito diversificadas do realismo e apontado para o fato de que elas aspiram à presença do real além do limite da representação. O público procura essa presença do real no testemunho das vivências mais violentas e cruéis e também na exposição da intimidade confessional e autobiográfica.

Soletras - Gostaríamos de focalizar aqui um dos livros organizados por você e por Heidrun Krieger Olinto, Literatura e realidade(s), de 2011, mais precisamente o início do capítulo de sua autoria, "Além ou aquém do realismo do choque" (p. 80). Citando Alan Badiou, você traz à cena a reflexão do filósofo sobre o real em sua existência nua, ou seja, sem nenhuma mediação teórica e conceitual. Quais as implicações dessa perspectiva, forte no século 20, para o entendimento do real no texto literário do século 21 ?

Ao procurar o real sem mediação, entramos no paradoxo de um encontro impossível ou "falho", disse Lacan em sua definição do real psicanalítico. Mesmo assim, o sujeito que sofre as consequências dessa presença no trauma carrega as marcas de sua impossibilidade, que é para o sujeito viver e sobreviver a algo tão forte que ameaça a existência dele próprio. Se para Lacan um dos sintomas é a repetição compulsiva desse mesmo evento, num esforço sintomático de preparar-se para ele "de novo", existe um vínculo fundamental com a maneira como o real, em forma de, por exemplo, a miséria, a violência e a barbárie em geral, é correspondido em nossa cultura por uma compulsiva representação repetitiva da mesma impossibilidade de transmitir para o público o que acontece na vivência privada de quem sofre com o evento. Esse elo entre o nível privado do psicanalítico e o público em sua expressão representativa reflete-se numa curiosa inversão em que o trauma é vivido em público ao mesmo tempo que o político torna-se um "affaire privado". Este traço caracteriza o que podemos chamar de uma "cultura do trauma" que no contemporâneo marca diferença

\footnotetext{
${ }^{1}$ Karl Erik Schøllhammer é professor associado e Diretor do Departamento de Letras da PUC-Rio. Pesquisador com bolsa de produtividade do CNPq, é Cientista do Nosso Estado da Faperj (2007-2009/2013-2016) e coordenador da Área de Letras da Faperj (2013) É autor, co-autor e editor de vários livros, entre eles: Linguagens da Violência (2000), Novas Epistemologias (2000), Literatura e Mídia (2002), Literatura e Cultura (2003), Literatura e Imagem (2005), Literatura e Memória (2006), Henrik Ibsen no Brasil (2008), Literatura e Crítica (2009) e Literatura e Realidade(s) (2010), Atrocity Exhibition (2011), Memórias do Presente (2012), Criatividade sem Limite? (2012) e Cenários Contemporâneos da Escrita (2013). De autoria integral os títulos mais recentes são: Além do visível - o olhar da literatura (2007), Ficção brasileira contemporânea $(2009,2011)$ e Cena do Crime (2013). http://lattes.cnpq.br/6021252419486141 email: karlerik@ @uc-rio.br
} 
com a moderna cultura do choque, na medida em que inverte o impulso exterior do choque para um apagamento da diferença entre exterior e interior, entre imaginação e realidade, entre fantasia e percepção. Olhar para o mundo da perspectiva do trauma oferece uma visão particular da história contemporânea, em que o presente é vivido como algo já "acontecido" porque já estávamos há tempos temendo o que finalmente acaba de ocorrer ou porque aparece repetindo eventos de uma gravidade insuperável do passado. De certa maneira significa que tudo o que pode ser desejado e imaginado para o futuro se deposita no passado e tudo no passado se apresenta em seu vir a ser futuro. Gumbrecht chama esta situação paradoxal de um "presente amplo" que acaba absorvendo a historicidade do passado-presente-futuro na experiência do simultâneo contemporâneo.

Soletras - No mesmo capítulo e ainda desenvolvendo a reflexão de Alan Badiou, você expõe um paradoxo que instala um dos principais temas do século - o fim da representação como verdade fiel. Transcrevemos:

Badiou destaca o poder do disfarce e do encobrimento como expressão do real, uma força, uma potência do falso que só é identificável através de uma forma ficcional que não pode ser confundida com o sentido. [...] Por outro lado, nada é suficientemente real para não ser suspeito de semelhança, suspeito de não ser real. Nada pode atestar o real a não ser o sistema de ficções no qual é desempenhado o papel de real. O que mais se apresenta como real mais se expõe à suspeita de não ser real, e a resposta a essa suspeita é o investimento em negatividade artística. [2011, p.81]

O que seria essa negatividade artística? Tem a ver com a tradição negativa que Nietzsche catalisa e que culmina com Adorno? Você pode citar algum exemplo em circulação, ou é um modo (composicional) de operar? Ou uma prática crítica?

O que Badiou diz aqui é que a própria representação, a potência do falso, tornou-se na modernidade tardia do século 20 parte constitutiva do real, uma observação que é parte do que Paul Ricoeur chamou de a filosofia da suspeita desenvolvida por seus três mestres, Marx, Nietzsche e Freud, todos acusando a aparência (linguagem, falsa consciência etc.) de atrapalhar e desvirtuar o acesso à verdade. É nesse registro que a crítica destrutiva se legitima e é ele que está por trás da ideia adorniana da dialética negativa. O crítico de arte Hal Foster fala de um ponto mais contemporâneo dos dois grandes paradigmas da imagem no modernismo tardio. Ou a imagem é vista indicando o caminho para a referência real, ou ela é vista como um simulacro que nos afasta da realidade. Em Andy Warhol, Foster encontra o artista cuja obra em alguns momentos se torna simultaneamente simulacral e referencial. Acontece por exemplo na série Morte e desastres, em que a imagem vira realidade e a realidade é o efeito traumático de uma imagem, ou nas reproduções de fotografias da imprensa de acidentes de trânsito, de linchamentos raciais e do retrato de Jackeline Kennedy. Foster vê essa fusão entre os dois paradigmas culminar no "realismo traumático", entendendo o trauma como um choque em segunda potência e nesse sentido como uma quebra da representação. Contra a limitação negativa dessa perspectiva, sugeri que as formas do realismo no contemporâneo se desdobram num repertório variado de afetos que vêm acompanhando o experimentalismo literário e artístico e que chamei de realismos afetivos.

Soletras - Em sua opinião, qual o impacto da imagem multimidiática sobre a construção do "real" no texto literário? 
Toda a mídia hoje é multimídia, e é exatamente a tensão criada entre as diferentes expressões que determina os significados do real e a maneira como o real ganha corpo. A literatura sempre dialogou com as outras artes, e hoje é particularmente a relação com as artes visuais e cênicas que dinamiza suas possibilidades. A escrita pode, de modo privilegiado, criar visualidades que ultrapassam os domínios do visível, e as artes cênicas também têm sido um forte fator de renovação na exploração pelas letras das opções performáticas e fáticas da literatura.

Soletras - Qual é o seu posicionamento a respeito das chamadas adaptações de textos literários para o cinema? É possível falar em termos gerais, ou cada processo de adaptação é único? Gostaria de lhe perguntar sobre um certo talento ou predileção do cinema dinamarquês pelas adaptações literárias. A adaptação do filme dinamarquês de Gabriel Axel A festa de Babette (1987), inspirado no conto homônimo de Karen Blixen(1885-1962), pseudônimo de Isak Dinesen, escritora também dinamarquesa - como você -, foi um marco: abriu uma vertente de produções cinematográficas correlacionando arte e comida.

A adaptação é um processo de tradução entre mídias que envolve uma nova interpretação e outras possibilidades expressivas; nesse sentido acho interessante. A questão sempre é se o resultado é bem-sucedido ou se se mostra inferior à obra original - o risco disso é grande. Entretanto, há exemplos destacados de adaptações para o cinema que não empobrecem o romance ou o conto, como a adaptação feita por Gabriel Axel. O filme se baseia num conto da escritora dinamarquesa Karen Blixen, e seu primeiro mérito foi introduzir uma obra literária genial para um público grande. Não foi apenas o gesto de galanteria de Hemingway ao dizer no discurso do prêmio Nobel que Karen Blixen, que escrevia sob o pseudônimo masculino Isak Dinesen, merecia o prêmio mais do que ele. Antes de Gabriel Axel, Orson Welles tentou fazer a mesma coisa com a adaptação do conto "A história imortal", , mas o filme, feito em Macau com participação da televisão francesa, nunca alcançou grande circulação. O segundo mérito cinematográfico de Gabriel Axel, além da direção muito boa, foi criar um espaço natural com a mesma austeridade moral que é o grande tema do conto. Blixen o escreveu em 1950, quando lhe pediram um conto sobre comida para a revista feminina Ladies' Home Journal". Mais tarde, "A festa de Babette" foi incluído no livro Anedotas do destino.

\footnotetext{
${ }^{2}$ Média metragem (58min) de 1968, dirigido por Orson Welles e inspirado no conto de Karen Blixen, publicado em português em 1985. Tanto este, quanto A Festa de Babette fazem parte do livro Anedotas do Destino. (Nota das editoras).

${ }^{3}$ Ladies' Home Journal é uma revista norte-americana que teve a sua primeira edição em 16 de fevereiro de 1883. Obtendo ampla aceitação entre as leitoras, tornou-se uma publicação líder para o público feminino norteamericano até os dias de hoje. Atualmente é publicada pela empresa Meredith Corporation. Foi a primeira revista a alcançar um milhão de leitores no ano de 1903. (N.E.).
} 